\title{
Task Structure as Moderator of College Principals' Leadership Behavior and Their Subordinates' Outcomes
}

\author{
Dr. Riffat-Un-Nisa Awan \\ Assistant Professor \\ Department of Education \\ University of Sargodha \\ E-mail: riffatawan@uos.edu.pk \\ Prof. Dr. Nayyar Raza Zaidi \\ Lahore School of Economics, Lahore \\ E-mail: drnayyar@lahoreschool.edu.pk \\ Ms. Anjum Naz \\ Lecturer \\ Department of Education \\ University of Sargodha \\ E-mail: anjumnaz@hotmail.com \\ Dr. Ghazala Noureen \\ Assistant Professor \\ Lahore College for Women University, Lahore \\ E-mail: g_noureen@yahoo.com
}

\begin{abstract}
This research article intended to investigate the moderating effect of structured task on the relationship of leadership behavior of degree college principals and their subordinates' job satisfaction, job expectancies and acceptance of leader. Data was collected from 640 college faculty members and 170 principals of degree colleges situated in 34 districts of the Punjab, Pakistan. The questionnaire for this study consisted of a combination of instruments. It comprised; a) four leader behaviors b) Task Structure c) acceptance of leader, d) Job Expectancies and e) the Job Descriptive Index. The questionnaire, which was administered to the principals, was Role Ambiguity Scale and Anxiety and Stress Scale. Data was analyzed using ANCOVA through SPSS. Results were twofold as findings of five hypotheses were according to the predictions of theory while the four hypotheses could not be verified and were found contradictory. Further tests are clearly needed for having sound evidence to evaluate the merits of the path-goal theory of leadership.
\end{abstract}

Keywords: Leadership Behavior, Path-Goal, Job Satisfaction, Task Structure, Job Expectancies

\section{Introduction}

Path-goal theory of leadership is a situational theory based on the assumption that effective leader behavior has a positive impact on subordinate job satisfaction, it provides a "functional" approach to leadership, calling for a diagnosis of functions which need to be fulfilled in subordinates' work environments for them to be motivated, perform at high levels, and be satisfied (Schriesheim and Neider, 1996). House (1971) formulated an elaborate version of the theory that includes situational variables. The theory has been further refined and extended (House 1996; House \& Dessler 1974; House \& Mitchell 1974). Assumptions of path goal theory regarding the nature of work include:

Role clarity is necessary for task accomplishment.

Highly structured tasks are less satisfying than unstructured tasks.

Higher level jobs entail less role clarity than do lower level job (House \& Dessler, 1974).

House and Mitchell (1974) recognized that the leader needs to complement only what is missing in a situation to enhance the subordinate's motivation, satisfaction, and performance. What is missing is determined by the environment, the task, and the competence and the motivation of the subordinate. Thus, the subordinate's productivity is enhanced if the leader provides needed structure to clarify unclear means and ends. Through the 
years much research have been conducted to test the hypotheses emerging out of the assumption of the theory) (Awan, 2003; Awan \& Zaidi, 2009; Awan, Zaidi \& Bigger, 2008; Dessler, 1973; Downey, Sheridan \& Slocum, 1975; House \& Dessler, 1974; House and Mitchell, 1974; Indvik, 1985; Podsakoff et al., 1984; Schriesheim et al., 1996; Schriesheim and Glinow, 1977; Schul, 1987; Wofford \& Liska, 1993).

The environmental variables of path-goal theory include, task structure, formal authority system, work group relations, and role ambiguity. These factors are not within the control of the subordinate but are important to satisfaction and the ability to perform effectively. Task structure (TS) is one of them. House \& Dessler (1974) define TS as the degree to which a task, job, work assignment, execution of rules and/or procedures is simple, repetitive, and unambiguous. A task with low structure is an ambiguous and poorly defined task; here "Structure" refers to the extent to which role relations are loosely or tightly arranged. TS also refers to the extent to which work is specified and certain (House \& Dessler's 1974).

Task structure is one of the variables that have probably received the most research attention among all the other environmental variables (Evans, 1996). Path-goal hypotheses containing the moderating variable TS are generated in the literature according to leader behavior. Directive leader behavior is one of the most frequently examined leader behaviors. It is often examined in terms of how it affects subordinate job satisfaction when moderated by TS. The purpose of directive leader behavior is to provide task information and role clarity and therefore, it should have a positive effect on subordinate expectancies, satisfaction, and performance when the task is complex, ambiguous, varied, pressured, or requires interdependence (House, 1971). When the ways to perform the task are routine and simple, subordinates will regard any further clarification by the leader as unnecessarily close supervision. Dessler (1997) stated that in highly structured situations a leader's additional attempts to structure the situation by closely supervising it or giving instructions, could backfire and reduce both morale and performance. Workers are likely to view it as redundant, excessive, and directed at keeping them working on unsatisfying tasks. On the other hand, when the tasks are non-routine and complex, an instrumental leadership style is appropriate. It helps subordinates to perform the task. House's theory predicts that the consideration displayed by the leader is most important when the work itself is irksome.

According to House and Mitchell (1974) leader directive behavior has a positive correlation with job satisfaction and the expectancies of subordinates who are engaged in ambiguous tasks. House and Dessler's (1974) study supported this theory. They establish that the initiation of structure (directive leader behavior) was found to negatively correlate with job satisfaction under highly structured tasks. Path-goal theory states that supportive leader behavior will positively impact the subordinates' satisfaction, who works on highly structured, stressful, frustrating or dissatisfying tasks (House and Mitchell, 1974). Moreover, it is hypothesized that participative leader behavior will also positively impact on subordinate outcomes when the task is unstructured, varied, or complex because it reduces ambiguity (House and Mitchell, 1974).

The reviews done by House and Dessler (1974) and House and Mitchell (1974) tended to confirm the theory. Wofford and Liskas' (1993) meta analytic study found that the prediction of TS moderates the relationship of initiating structure with expectancy I, was not supported. However, TS was found to be a moderator for the relationship of initiating structure with Expectancy II. TS was found to have a positive moderating effect on the relationship between consideration and satisfaction with supervision. In Indvik's (1985) study when structure was absent from the work environment, directive, structuring leadership behavior contributed to the intrinsic motivation of subordinates, their satisfaction with the leader, and their overall satisfaction.

Direct tests of the theory by Dessler (1973) were also supportive who found that leader's initiation structure was correlated less with the subordinates' satisfaction and role clarity as the ambiguity of the task decreased. Considerate, supportive leadership behavior in a highly structure work setting, did enhance motivation, satisfaction, performance, and role clarity, as expected. Participative leadership provided the most overall satisfaction to subordinates who preferred and experienced a low task structure. Studies conducted by Awan (2003) Dessler, (1973) House (1971) House and Dessler (1974) Schriesheim and Glinow (1977) found support for task structure on supportive leader behavior but Schriesheim and Glinow (1977) did not confirm path-goal hypothesis for task structure on instrumental leader behavior.

In conclusion, there appeared to be mixed findings out of different researches some of which confirmed and suggest acceptance of identified path-goal hypotheses regarding specific leader behavior to job satisfaction when moderated by the variable TS while, some others did not confirmed and rejected the path-goal hypotheses. To explain the very reasons of the rejection of path-goal hypotheses different measures were taken. Schriesheim and his collegues (2006) concern is that quality of the measures is often poor that have been used in previous path-goal theory tests. This shortcoming is believed to have limited the level of support for the theory (House, 1996) and this concern is more 
directly addressed in this research by using the measures which are developed specifically for testing this theory. This study intends to test path-goal assumption as discussed above and tries to find out the moderating effect of structured task on the relationship of leadership style of degree college principals and their subordinates' outcomes in an educational setting in Pakistan.

\section{Research Question}

What is the relationship between leader behavior and subordinates' acceptance of leader, job expectancies and job satisfaction when the task is highly structured, holding constant the effect of principals' role ambiguity and stress?

\section{Method}

For the present study data was collected from thirty four districts of Punjab. Six degree colleges ( 3 male, 3 female) from each district were selected randomly. There were some remote districts where the number of colleges was less than six so all colleges from those districts were included in the sample and consequently the sample size was 170 . From each college 4 teachers were selected randomly. In this way 680 teachers (lecturers, Assistant professors, Associate professors, professors) working in 170 Government degree colleges were the part of study. All the principles of 170 colleges were involved in this study. Finally, 640 questionnaires were analyzed after excluding non-respondents and incomplete questionnaires for teachers and 165 for principals. The tool used for the data collection was a self-administered questionnaire which consisted of a combination of instruments. There were four sets of questions that measured the four leader behaviors (House and Dessler, 1974; House and Mitchell (1974), first for measuring TS (House and Dessler, 1974), second for measuring acceptance of leader, third combination of questions measured job expectancies (House \& Dessler, 1974) and the fourth which was Job Descriptive Index (Smith, Kendall, \& Hulin, 1969) for measuring Job Satisfaction. The Job Descriptive Index was divided into six components. The questionnaire, which was administered to the principals, was role ambiguity scale (Rizzo, House, and Lirtzman, 1970) and anxiety and stress scale. These two variables were included in the design of study as covariates.

A pilot study was conducted using a total of 39 college teachers as the sample. So far as reliability of measuring instrument was concerned, the instruments in their original had high reliability and validity but in a different context. As the instruments were used with a different population, this warranted establishment of their reliability and validity afresh. The reliability coefficient ranged from 0.72 to 0.91 for all the instruments used in this research.

Analysis

Multivariate analysis of covariance (MANCOVA) and univariate analysis of covariance (ANCOVA) at .05 level of significance, were used to test the hypotheses of this study. Scatter grams were also visually examined on SPSS to determine linearity between variables. Before conducting an ANCOVA, the homogeneity-of-slopes assumption was first tested. Wiersma, (1995) explains that if the interaction between factor and covariate is significant, the results from an ANCOVA are not meaningful, and ANCOVA should not be conducted. This assumption was observed in this study and the tests of homogeneity-of-slopes were conducted on all possible combinations of variables. The covariate that came up with non-significant interaction was included in data analysis. As a result of this analysis all combinations of achievement oriented leadership and dependent variables were excluded from the analysis. Following hypotheses were investigated in this research.

$\boldsymbol{H}_{\boldsymbol{o} \mathbf{1}}$. There is no relationship between directive leader behavior and subordinates' acceptance of leader, when the task is highly structured, holding constant the effect of principals' stress.

$\boldsymbol{H}_{\boldsymbol{o} 2}$. There is no relationship between supportive leader behavior and subordinates' acceptance of leader, when the task is highly structured, holding constant the effect of principals' role ambiguity.

$\boldsymbol{H}_{\boldsymbol{o} \text { 3. }}$ There is no relationship between participative leader behavior and subordinates' acceptance of leader, when the task is highly structured, holding constant the effect of principals' role ambiguity and stress.

$\boldsymbol{H}_{\boldsymbol{o}}$. There is no relationship between directive leader behavior and subordinates' job expectancies, when the task is highly structured, holding constant the effect of principals' role ambiguity and stress.

$\boldsymbol{H}_{\boldsymbol{o}}$. There is no relationship between supportive leader behavior and subordinates' job expectancies, when the task is highly structured, holding constant the effect of principals' role ambiguity and stress.

$\boldsymbol{H}_{\boldsymbol{o} \text { 6. }}$ There is no relationship between participative leader behavior and subordinates' job expectancies, when the task is highly structured, holding constant the effect of principals' role ambiguity and stress.

$\boldsymbol{H}_{\boldsymbol{o}}$. There is no relationship between supportive leader behavior and subordinates' job satisfaction, when the task is highly structured holding constant the effect of principals' role ambiguity. 
$\boldsymbol{H}_{\boldsymbol{o g}}$. There is no relationship between directive leader behavior and subordinates' job satisfaction, when the task is highly structured holding constant the effect of principals' role ambiguity.

$\boldsymbol{H}_{\boldsymbol{o}}$. There is no relationship between participative leader behavior and subordinates' job satisfaction, when the task is highly structured holding constant the effect of principals' role ambiguity and stress.

Tables and their description is at the end of paper

\section{Conclusions}

On the bases of findings of the study, following conclusions were drawn:

\section{Results supported the theory}

$\boldsymbol{H}_{\boldsymbol{o 1}}$. The subjects working under directive leadership had inverse relationship with acceptance of leader when the task was structured.

$\boldsymbol{H}_{\boldsymbol{o z}}$. The people working under high participative leadership have inverse relationship with acceptance of leader when the task is structured.

$\boldsymbol{H}_{\boldsymbol{o 5}}$. Test revealed that people put more effort in their work when the leaders were high supportive with a structured task situation.

$\boldsymbol{H}_{\boldsymbol{o s}}$. Results indicated that the people were less satisfied when the leaders were high directive with a structured task situation. High directive leadership contributed negatively in job satisfaction with supervision, coworker and job in general.

$\boldsymbol{H}_{\boldsymbol{o g}}$. High directive leadership and high participative leadership contributed negatively in job satisfaction with supervision, coworker and job in general when the task was structured.

\subsection{Results not Supporting Path-Goal Theory}

$\boldsymbol{H}_{\boldsymbol{o} \text { 2. }}$ It was concluded that subjects working under supportive leadership have inverse relationship with acceptance of leader when the task is structured.

$\boldsymbol{H}_{\boldsymbol{o} \text { 4. }}$ The subjects working under high directive leadership have positive relationship with job expectancies when the task is structured.

$\boldsymbol{H}_{\boldsymbol{o} \text { 6. }}$ It was concluded that subjects working under high participative leadership have positive relationship with job expectancies and were more motivated, when the task is structured.

$\boldsymbol{H}_{\boldsymbol{o} \text { 7. }}$ High supportive leadership contributed negatively in job satisfaction.

\section{Discussion and Implications of Findings for Path-Goal Theory}

So far as the testing of path-goal theory was concerned this study came up with mixed results. Some predictions of the theory were supported while others were not. The findings reflected many significant relationships among the three leader behaviors through take structure as moderating variable to the nine dependent variables but all results were not according to the prediction of path-goal theory.

It was found, as was predicted in path-goal theory that directive leader behavior had a negative effect on subordinate's job satisfaction when the task was dissatisfying or structured. This finding was in line with the Indvik (1985) study who concluded that leader behavior had a certain effect on job satisfaction when task structure was considered as a moderating variable. High directive leadership contributed negatively in job satisfaction with supervision, coworker and job in general when the task was structured. This finding confirmed the path-goal theory that subordinates were more satisfied with directive and participative leaders in an unstructured task. In path- goal theory, it is predicted that since the purpose of directive leader behavior is to provide task information and role clarity, it will have a positive effect on subordinates' expectancies, job satisfaction and performance when the task is complex, ambiguous and varied (House, 1971). Therefore, there would be a negative correlation with subordinates' job expectancies, job satisfaction and acceptance of leader, who are engaged in clear tasks for directive leaders.

According to path-goal theory, supportive leader behavior will have positive effect on subordinate satisfaction for subordinates who work on highly structured tasks and will have little effect on job satisfaction or performance when task structure is low (House and Mitchell, 1974). The results of this study revealed the fact that the people were more satisfied when the leaders were highly supportive with a structured task situation. This result confirmed the path-goal theory that when subordinates have a task that was structured or routine a supportive and considerate leader motivates a subordinate by minimizing the negative aspects of the work environment. Path-goal theory hypothesizes that participative leader behavior will have a positive impact on subordinate outcomes when the task is unstructured' varied or complex. The results showed that the high participative leadership contributed negatively in 
job satisfaction with supervision, coworker and job in general when the task was structured. All above results confirmed the findings of Dessler (1973), House and Mitchell (1974), House and Dessler (1974), Schriesheim and Glinow (1977) Podsakoff et al., (1984), Indvik (1985) Wofford \& Liska (1993).

This study did not support the hypotheses related to supportive leader behavior, acceptance of leader and job satisfaction. It was concluded that subjects working under supportive leadership had inverse relationship with acceptance of leader and job satisfaction when the task was structured. This result was contrary to path-goal theory, because theory states that when the task is highly structured supportive leadership makes the work tolerable and pleasant and people are more comfortable with supportive leader. It was concluded that subjects working under high directive and participative leadership have positive relationship with job expectancies and were more motivated, when the task was structured. This result was contradictory to path-goal theory, because theory states that when the task is highly structured a non-directive leadership behavior motivates the subordinate to increased performance. It also states that participative leadership has positive effect on motivation of subordinates when the task is unstructured. Many researchers have reported the findings contradictory to path-goal theory and this result evidence seems to support them. (Downey, Sheridan and Slocum 1979; Indvik, 1985; Schriesheim and Glinow 1977; Wofford \& Liska, 1993).

\section{Final Words}

The findings of this study guide educational administrators that they should work in a very supportive and friendly manner when the teachers who are working on repetitive, boring and structured assignments. Heads and principals must work closely with the teachers in a non repetitive ambiguous task for providing them direction when and where needed for making them satisfied and motivated. Further tests are clearly needed for having enough solid empirical evidence to evaluate the merits of the path-goal theory of leadership. Future research must examine task structure in combination with other moderating variables especially the perceived ability of the employees because highly skilled workers can better cope with non-repetitive and ambiguous situations. To generate more useful information about leader behavior, research of this nature must be conducted, particularly the effects of supervisory reward and punishment behaviors on employees' outcomes.

\section{References}

Awan, R.N. (2003). A Study of Relationship among Leadership Behavior of College Principals and their Subordinates' Job Satisfaction and Acceptance of Leader: A Path-Goal Approach. Unpublished Doctoral Dissertation. University of the Punjab. Pakistan.

Awan, R.N. \& Zaidi, N.R. (2009). A Study of Path-goal Relations between Leaders of College Principals and their Subordinates in Pakistan. Journal of College Teaching and Learing. 6 (7), 31-40.

Awan, R.N., Zaidi, N.R \& Bigger, S. (2008). Relationships between Higher Education Leaders and Subordinates in Pakistan: A Path-Goal Approach. Bulletin of Education and Research. 30 (2) 29-44.

Dessler, G. (1973). An investigation of a path-goal theory of leadership. Dissertation Abstract International, City University of New York. VOL. 34-02A.

Dessler, G. (1982). Organization and management. Virginia: Preston Pub. Co. Inc.

Dessler, G. (1997). Management: leading people and organizations in the $21^{\text {st }}$ Century, NJ: Prentice Hall.

Downey, H. K., J. E. Sheridan, and J. W. Slocum. (1975). Analysis of Relationships Among Leader Behavior, Subordinate Job Performance and Satisfaction: A Path-Goal Approach," Academy of Management Journal, Vol. 18 253-262.

Evans, M. C. (1996). R.J. HOUSE'S “A Path-Goal Theory of Leader Effectiveness” Leadership Quarterly, 7(3), 305-309.

House R. J. (1971). A path goal theory of leader effectiveness, Administrative Science Quarterly, 16, 3, 321-338.

House, R. J. (1996). Path-goal theory of leadership: Lessons, legacy, and a reformulated theory, Leadership Quarterly, 7-3, 323-325.

House, R. J. \& Baetz, M.L. (1979). Leadership: Some empirical generalizations and new research directions. Research in Organizational Behavior, 1,341-423.

House, R. J. \& Dessler, G. (1974). Path goal theory of leadership: Some post hoc and a priori tests. In Contingency approaches to leadership, JG Hunt and L.L. Larson (Eds.), Carbondale, IL: Southern Illinois University.

House, R. J. \& Mitchell,T.R. (1974). Path goal theory of leadership in Fred Luthans (ed.) Contemporary Readings in Organizational Behavior. New York: McGraw Hill. 
Indvik, J. (1985). A path-goal theory: Investigation of superior-subordinate relationships (Leadership, Downward communication, Supervision). The University of Wisconsin-Madison. Dissertation Abstract International, Vol. 46-12A.

Levanoni, E. \& Knoop, R. (1985). Does task structure moderate the relationship of leaders' behavior and employees' satisfaction? Psychological Reports, 57: 61 1-623.

Podsakoff, P. M., Todor, W. D., Grover, R. A. and Huber, V. L. (1984) Situational Moderators of Leader Reward and Punishment Behaviors: Fact or Fiction? Organizational Behavior and Human Performance 34, 21-63

Schriesheim C. A. and Neider, L.L. (1996). Path-Goal Leadership Theory: The Long And Winding Road. Leadership Quarterly, 7(3), 317-321.

Schriesheim, C., Castro, S. L., Zhou, X., DeChurch, L. A (2006). An investigation of path-goal and transformational leadership theory predictions at the individual level of analysis. The Leadership Quarterly 17 21-38

Schriesheim, C.A. \& Von Glinow, M.A. (1977). The Path-Goal Theory of Leadership: A Theoretical and Empirical Analysis. The Academy of Management Journal, Vol. 20, No. 3, pp. 398-405

Schul, P. L. (1987). An Investigation of Path-Goal Leadership Theory and Its Impact on Intrachannel Conflict and Satisfaction. Journal of the Academy of Marketing Science. 15, No. 4, 042-052

Wofford, J. C. and Liska, L. Z. (1993). Path-Goal Theories of Leadership: A Meta-Analysis. Journal of Management. Vol. 19, No. 4, 857-876

Wiersma, W. (1995). Research Methods in Education: An Introduction (6th Ed.) Allyn \& Bacon

Table 1. N, Mean, Adjusted Mean, Standard Deviation, and ANCOVA for Directive Leadership Behavior and Acceptance of Leader when the Task is Structured

\begin{tabular}{llccclrrrr}
\hline & N & $\begin{array}{c}\text { Adjusted } \\
\text { Mean }\end{array}$ & Mean & $S D$ & Sources of variance & $d f$ & $F$ & $P$ & $\eta^{2}$ \\
\hline Directive-o & 89 & 25.330 & 25.33 & 5.42 & Between groups(adjusted) & 2 & 59.865 & .000 & .159 \\
Directive-low & 523 & 29.202 & 29.20 & 4.23 & Within groups & 633 & & \\
Directive-high & 25 & 21.034 & 21.04 & 7.81 & Total & 637 & & \\
\hline
\end{tabular}

Adjusted Means are Evaluated at covariate appeared in the model.

A one way analysis of covariance ANCOVA was conducted. The independent variable was directive leadership behaviour, the dependent variable was acceptance of leader, moderating variable was task structure and covariate was principals' stress. ANCOVA was significant, $F(2$, $637)=59.867, p=.000$ and $\eta^{2}=.159$. The strength of relationship was quite strong because $16 \%$ variance in the dependent variable was due to directive leadership behavior. The null hypothesis was rejected for ANCOVA F test and a significant cause effect relationship was established between the independent and dependent variable. It means that when the task is structured directive leadership has significant effect on acceptance of leader.

The means of the acceptance of leader adjusted for initial differences were ordered across the three leadership behaviours. The low directive leadership had the largest adjusted mean $(M=29.202)$, and high directive leadership had the smallest adjusted mean $(N=21.034)$. Since $F$-ratio was significant, so it was decided to run LSD Post Hoc test of multiple comparison. However only significant mean differences between low and high directive leadership are discussed here.

Table 1a. LSD Post Hoc Test of Multiple Comparisons

\begin{tabular}{cccc}
\hline \multicolumn{1}{c}{ Dependent Variable } & Comparison & Mean difference (I-J) & Sig. \\
\hline Acceptance of leader & High Directive Vs low Directive & -8.168 & .000 \\
\hline
\end{tabular}

There were significant differences in the adjusted means between high directive and low directive leadership behavior. After this test it was concluded that subjects working under directive leadership had inverse relationship with acceptance of leader when the task was structured.

Table 2. N, Mean, Adjusted Mean, Standard Deviation, and ANCOVA for Supportive Leadership Behavior and Acceptance of Leader when the Task is Structured

\begin{tabular}{lccccccccc}
\hline & N & $\begin{array}{c}\text { Adjusted } \\
\text { Mean }\end{array}$ & Mean & $S D$ & Sources of variance & $d f$ & $F$ & $P$ & $\eta^{2}$ \\
\hline Supportive-0 & 165 & 27.002 & 27.00 & 3.75 & Between groups(adjusted) & 2 & 194.906 & .000 & .381 \\
Supportive-low & 329 & 31.105 & 31.11 & 3.07 & Within groups & 634 & & \\
Supportive-high & 144 & 23.597 & 23.60 & 5.56 & Total & 638 & & \\
\hline
\end{tabular}


Adjusted Means are Evaluated at covariate appeared in the model.

The above table shows the results of a one way analysis of covariance ANCOVA. The independent variable was supportive leadership behavior, the dependent variable was acceptance of leader, moderating variable was task structure and covariate was principals' stress. ANCOVA was significant, $F(2,638)=194.906, p=.000, \eta^{2}=.38$. The strength of relationship was quite strong because $38 \%$ variance in the dependent variable was due to supportive leadership behavior. It means that when the task is structured supportive leadership has significant effect on acceptance of leader.

The Low supportive leadership had the largest adjusted mean $(M=31.105)$, and high supportive the smallest adjusted mean $(N=23.597)$. Since F-ratio was significant, so it was decided to run LSD Post Hoc Test of Multiple Comparison. However only significant mean differences between high supportive and low supportive are discussed here.

Table 2a. LSD Post Hoc Test of Multiple Comparison

\begin{tabular}{cccc}
\hline DV & Comparison & Mean difference (I-J) & Sig. \\
\hline Acceptance of leader & High supportive Vs low supportive & -7.508 & .000 \\
\hline
\end{tabular}

There were significant differences in the adjusted means between high supportive and low supportive leadership behaviour. After this test the researchers concluded that subjects working under supportive leadership had inverse relationship with acceptance of leader when the task was structured.

Table 3. N, Mean, Adjusted Mean, Standard Deviation, and ANCOVA for Participative Leadership Behavior and Acceptance of Leader when the Task is Structured

\begin{tabular}{|c|c|c|c|c|c|c|c|c|c|}
\hline & $\mathrm{N}$ & $\begin{array}{c}\text { Adjusted } \\
\text { Mean }\end{array}$ & Mean & $S D$ & Sources of variance & $D f$ & $F$ & $P$ & $\eta^{2}$ \\
\hline Participative-o & 164 & 27.372 & 27.38 & 3.79 & Between groups(adjusted) & 2 & 159.289 & .000 & .334 \\
\hline Participative -low & 320 & 30.983 & 30.99 & 3.20 & Within groups & 635 & & & \\
\hline Participative -high & 156 & 23.991 & 23.97 & 5.66 & Total & 640 & & & \\
\hline
\end{tabular}

Adjusted Means are Evaluated at covariate appeared in the model.

A one way analysis of covariance ANCOVA was conducted. The independent variable was participative leadership behavior, the dependent variable was acceptance of leader, moderating variable was task structure and covariate was principals' role ambiguity and stress. ANCOVA was significant, $F(2,640)=159.289, p=.000 . \eta^{2}=.334$. The strength of relationship was quite strong because $33 \%$ variance in the dependent variable was due to leadership behavior. It means that when the task is structured participative leadership had significant effect on acceptance of leader. The high participative leadership had the smallest adjusted mean $(M=23.991)$, and low participative had the largest adjusted mean $(N=$ 30.983).

Table 3a. LSD Post Hoc Test of Multiple Comparisons

\begin{tabular}{cccc}
\hline DV & Comparison & Mean difference (I-J) & Sig. \\
\hline Acceptance of leader & High Participative Vs low Participative & -6.992 & .000 \\
\hline
\end{tabular}

There were significant differences in the adjusted means between high participative and low participative leadership behaviors. After this test it was concluded that subjects working under high participative leadership had inverse relationship with acceptance of leader when the task was structured.

Table 4. MANCOVA for Directive Leadership Behavior and Job Expectancies when the Task is Structured

\begin{tabular}{|c|c|c|c|c|c|c|}
\hline$\underline{\text { Test }}$ & $\Lambda$ value & $\underline{F \text {-Ratio }}$ & & thesis $d f$ & $\underline{P}$ & n-Square \\
\hline Wilks' lambda & .887 & 19.509 & & 4.00 & .000 & .058 \\
\hline DVs & & & $F$-Ratio & $d f$ & $P$ & $\eta$-Square \\
\hline Expectancy I & & & 337.46 & $(2,637)$ & .000 & .064 \\
\hline Expectancy II & & & 690.168 & $(2,637)$ & .000 & .107 \\
\hline
\end{tabular}

The table shows the results of multivariate analysis of covariance. MANCOVA was conducted to determine the effect of the directive leadership behavior on the job expectancies when the task is structured holding constant the effect of principals' role ambiguity and stress. Significant differences were found among the four leadership behaviors on the dependent measures, Wilks' Lambda $\Lambda=.887, F(4,1268)=19.509, P=.000$, was significant.

Analyses of covariance on each dependent variable were conducted as follow up tests to the MANCOVA. The ANCOVA on Expectancy I and Expectancy II was significant, $F(2,637)=337.46, P<.000 . \eta^{2}=.064 . F(3,754)=690.168, P<.000 . \eta^{2}=.107$. It means that significant differences were found among the directive leadership behavior on the dependent measure of Expectancy I and Expectancy II. To see which leadership behavior is more effective LSD post hoc test of multiple comparison was conducted. 
Table 4a. LSD Post Hoc Test of Multiple Comparisons

\begin{tabular}{llcc}
\hline \multicolumn{1}{c}{ DV } & \multicolumn{1}{c}{ Comparison } & Mean difference (I-J) & Sig. \\
\hline Expectancy I & High directive Vs low directive & 1.729 & .000 \\
Expectancy II & High directive Vs low directive & 2.539 & .000 \\
\hline
\end{tabular}

There were significant differences in the adjusted means between high directive and low directive leadership behaviors. After this test it was concluded that subjects working under high directive leadership had positive relationship with job expectancies when the task was structured.

Table 5. MANCOVA for Supportive Leadership Behavior and Job Expectancies

\begin{tabular}{|c|c|c|c|c|c|}
\hline$\underline{\text { Test }}$ & $\Lambda$ value & $\underline{F-\text { Ratio }}$ & $\underline{\text { Hypothesis } d f}$ & $\underline{P}$ & $\underline{\eta}$-Square \\
\hline Wilks' lambda & .880 & 20.78 & 4.00 & .000 & .062 \\
\hline DVs & & $F$-Ratio & $d f$ & $P$ & $\eta$-Square \\
\hline Expectancy I & & 35.010 & $(2,637)$ & .000 & .091 \\
\hline Expectancy II & & 49.566 & $(2,637)$ & .000 & .124 \\
\hline
\end{tabular}

A one-way multivariate analysis of covariance (MANCOVA) was conducted to determine the effect of the three types of supportive leadership behaviors on the job expectancies when the task is structured. Significant differences were found among the supportive leadership behaviors on the dependent measures, Wilks' Lambda $\Lambda=.880, F(4,1264)=20.78, P=.000$, was significant. The multivariate $\eta^{2}$ based on Wilks' $\Lambda$ was not so strong.

Analysis of covariance (ANCOVA) on each dependent variable was conducted as follow up tests to the MANOVA. Each ANCOVA was tested at the .05 level of significance. The ANCOVA for both the dependent variables were significant, Expectancy I, $F(2,637)=35.01, P<.000 . \eta^{2}=$ 071. Expectancy II, $F(2,637)=49.566, P=.000 . \eta^{2}=114$. It means that significant differences were found among the three supportive leadership dimensions on the dependent measure of job expectancies.

Table 5a. LSD Post Hoc Test of Multiple Comparisons

\begin{tabular}{clcc}
\hline \multicolumn{1}{c}{ DV } & \multicolumn{1}{c}{ Comparison } & Mean difference (I-J) & Sig. \\
\hline Expectancy I & High supportive Vs low supportive & 1.895 & .000 \\
Expectancy II & High supportive Vs low supportive & 2.602 & .000 \\
\hline
\end{tabular}

Follow up test revealed that people put more effort in their work when the leaders were high supportive with a structured task situation.

Table 6. MANCOVA for Participative Leadership Behavior and Job Expectancies

\begin{tabular}{|c|c|c|c|c|c|c|}
\hline$\underline{\text { Test }}$ & $\Lambda$ value & $\underline{F \text {-Ratio }}$ & & Hypothesis $d f$ & $\underline{P}$ & $\underline{\eta}$-Square \\
\hline Wilks' lambda & .887 & 19.509 & & 4.00 & .000 & .058 \\
\hline DVs & & & $F$-Ratio & $d f$ & $P$ & $\eta$-Square \\
\hline Expectancy I & & & 337.46 & $(2,637)$ & .000 & .064 \\
\hline Expectancy II & & & 690.168 & $(2,637)$ & .000 & .107 \\
\hline
\end{tabular}

Table shows the results of multivariate analysis of covariance (MANCOVA). MANCOVA was conducted to determine the effect of the participative leadership behaviours on the job expectancies when the task is structured holding constant the effect of principal's role ambiguity and stress. Significant differences were found among the four leadership behaviours on the dependent measures, Wilks' Lambda $\Lambda=.887, F$ $(4,1268)=19.509, P=.000$, was significant.

Analysis of covariance (ANCOVA) on each dependent variable were conducted as follow up tests to the MANCOVA. Each ANCOVA was tested at the .05 level of significance. The ANCOVA on Expectancy I and Expectancy II was significant, $F(2,637)=337.46, P<.000$. $\eta^{2}=064$. $F(3,754)=690.168, P<.000 . \eta^{2}=.107$. It means that significant differences were found among the participative leadership behaviors on the dependent measure of Expectancy I and Expectancy II. To see which leadership behavior is more effective LSD post hoc test of multiple comparison was conducted.

Table 6a. LSD Post Hoc Test of Multiple Comparisons

\begin{tabular}{|c|c|c|c|}
\hline DV & Comparison & Mean difference (I-J) & Sig. \\
\hline Expectancy I & High Participative Vs low Participative & 1.729 & .000 \\
\hline Expectancy II & High Participative Vs low Participative & 2.539 & .000 \\
\hline
\end{tabular}

Follow up test reveal that people were more motivated with high participative leadership when the task was structured. 
Table 7. MANCOVA for Supportive Leadership Behavior and Job Satisfaction

\begin{tabular}{|c|c|c|c|c|c|}
\hline$\underline{\text { Test }}$ & $\Lambda$ value & $\underline{F \text {-Ratio }}$ & Hypothesis $d f$ & $\underline{P}$ & 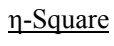 \\
\hline Wilks' lambda & .904 & 5.425 & 12.00 & .000 & .049 \\
\hline DVs & & $F$-Ratio & $d f$ & $P$ & $\eta$-Square \\
\hline Work & & 2.618 & $(2,634)$ & .074 & .008 \\
\hline Pay & & 8.720 & $(2,634)$ & .000 & .027 \\
\hline Promotion & & 5.753 & $(2,634)$ & .003 & .018 \\
\hline Supervision & & 23.039 & $(2,634)$ & .000 & .068 \\
\hline Coworker & & 8.670 & $(2,634)$ & .000 & .027 \\
\hline Job in general & & 2.838 & $(2,634)$ & .009 & .015 \\
\hline
\end{tabular}

A one-way multivariate analysis of covariance (MANCOVA) was conducted to determine the effect of supportive leadership behavior on the six dependent variables when the task was structured, holding constant the effect of principals' role ambiguity. Significant differences were found among the supportive leadership behaviors on the dependent measures, Wilks' Lambda $\Lambda=.904, F(12,1252)=5.425, P=.000$, was significant. Analysis of covariance (ANCOVA) on each dependent variable was conducted as follow up tests to the MANCOVA. The ANCOVA on all job satisfaction facets except work was significant; it means that significant differences were found among the three supportive leadership behaviors.

Table 7a. LSD Post Hoc Test of Multiple Comparisons

\begin{tabular}{llrr}
\hline \multicolumn{1}{c}{ DV } & \multicolumn{1}{c}{ Comparison } & Mean difference (I-J) & Sig. \\
\hline Work & High Supportive Vs low Supportive & -1.466 & .003 \\
Pay & High Supportive Vs low Supportive High Supportive & -3.050 & .022 \\
Promotion & Vs low Supportive & -1.813 & .000 \\
Supervision & High Supportive Vs low Supportive & -7.167 & .001 \\
Coworker & High Supportive Vs low Supportive & -2.392 & .000 \\
Job in general & High Supportive Vs low Supportive & -1.727 & .001 \\
\hline
\end{tabular}

Follow up tests to the ANCOVA were also conducted to evaluate pair wise differences among the adjusted means, after this test the researchers concluded that high supportive leadership contributed negatively in job satisfaction

Table 8. MANCOVA for Directive Leadership Behavior and Job Satisfaction

\begin{tabular}{|c|c|c|c|c|c|}
\hline Test & 1 value & $\underline{F \text {-Ratio }}$ & Hypothesis $d f$ & $\underline{P}$ & 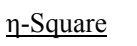 \\
\hline Wilks' lambda & .964 & 1.940 & 12.00 & .026 & .018 \\
\hline $\mathrm{DVs}$ & & $F$-Ratio & $d f$ & $P$ & $\eta$-Square \\
\hline Work & & .741 & $(2,634)$ & .477 & .002 \\
\hline Pay & & 2.528 & $(2,634)$ & .081 & .008 \\
\hline Promotion & & 1.465 & $(2,634)$ & .232 & .005 \\
\hline Supervision & & 7.591 & $(2,634)$ & .001 & .024 \\
\hline Coworker & & 1.511 & $(2,634)$ & .221 & .005 \\
\hline Job in general & & 2.838 & $(2,634)$ & .050 & .019 \\
\hline
\end{tabular}

A one-way multivariate analysis of covariance (MANCOVA) was conducted to determine the effect of directive leadership behaviors on the six dependent variables when the task is structured, holding constant the effect of principals' role ambiguity. Significant differences were found among the directive leadership behaviors on the dependent measures, Wilks' lambda $\Lambda=.964, F(12,1250)=1.940, P=.026$, was significant. The ANCOVA on supervision and coworker and job in general was significant, It means that significant differences were found among the three directive leadership behaviors on the dependent measure of supervision and job in general.

Table 8a. LSD Post Hoc Test of Multiple Comparisons

\begin{tabular}{llcc}
\hline \multicolumn{1}{c}{ DV } & Comparison & Mean difference (I-J) & Sig. \\
\hline Pay & High Directive Vs low Directive & -5.673 & .013 \\
Coworker & High Directive Vs low Directive & -2.813 & .018 \\
\hline
\end{tabular}

Follow up tests to the ANCOVA were also conducted to evaluate pair wise differences among three adjusted means, After this test it was concluded that high directive leadership contributed negatively in job satisfaction with supervision, coworker and job in general. 
Table 9. MANCOVA for Participative Leadership Behavior and Job Satisfaction

\begin{tabular}{|c|c|c|c|c|c|}
\hline$\underline{\text { Test }}$ & $\Lambda$ value & $\underline{F \text {-Ratio }}$ & Hypothesis $d f$ & $\underline{P}$ & n-Square \\
\hline Wilks' lambda & .921 & 4.416 & 12.00 & .000 & .041 \\
\hline DVs & & $F$-Ratio & $d f$ & $P$ & $\eta$-Square \\
\hline Work & & 3.850 & $(2,637)$ & .022 & .012 \\
\hline Pay & & 2.035 & $(2,637)$ & .132 & .006 \\
\hline Promotion & & 1.984 & $(2,637)$ & .138 & .006 \\
\hline Supervision & & 17.569 & $(2,637)$ & .000 & .053 \\
\hline Coworker & & 7.337 & $(2,637)$ & .001 & .023 \\
\hline Job in general & & 9.393 & $(2,637)$ & .000 & .029 \\
\hline
\end{tabular}

A multivariate analysis of covariance (MANCOVA) was conducted to determine the effect of participative leadership behavior on the six dependent variables when the task is structured, holding constant the effect of principals' stress and role ambiguity. Significant differences were found among the participative leadership behaviors on the dependent measures, Wilks' Lambda $\Lambda=.921, F(12,1254)=4.416, P=.000$, was significant.

Analysis of covariance (ANCOVA) on each dependent variable was conducted as follow up tests to the MANCOVA. The ANCOVA on pay and promotion was non-significant, It means that significant differences were found among the three participative leadership behaviors on the dependent measure of work, supervision, coworker and job in general.

Table 9a. LSD Post Hoc Test of Multiple Comparisons

\begin{tabular}{llrr}
\hline \multicolumn{1}{c}{ DV } & \multicolumn{1}{c}{ Comparison } & Mean difference (I-J) & Sig. \\
\hline Work & High participative Vs low participative & -1.737 & .006 \\
Supervision & High participative Vs low participative & -6.269 & .000 \\
Coworker & High participative Vs low participative & -2.251 & .001 \\
Job in general & High participative Vs low participative & -2.381 & .000 \\
\hline
\end{tabular}

Follow up tests to the ANCOVA to evaluate pair wise differences among three adjusted means were also conducted, After this test the researchers concluded that high participative leadership contributed negatively in job satisfaction with work, supervision, coworker and job in general. 